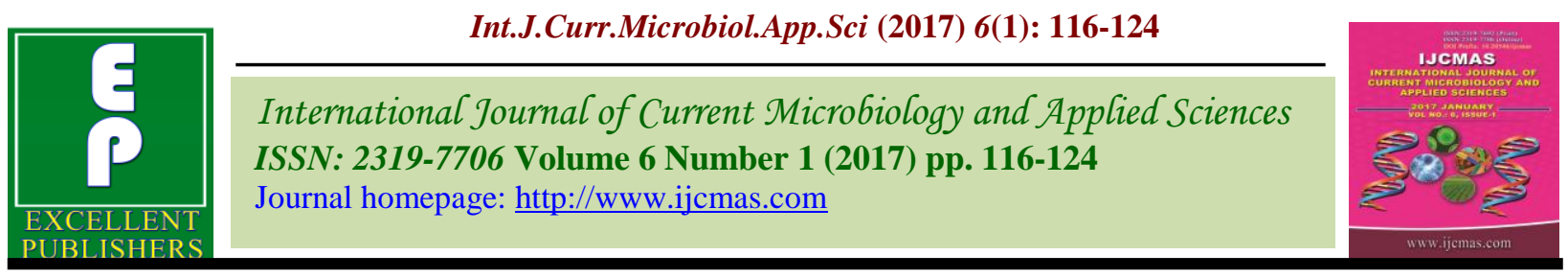

Original Research Article

http://dx.doi.org/10.20546/ijcmas.2017.601.015

\title{
Vitality of Pro-Inflammatory Cytokine, Scavenger Receptor Proteins and Atherosclerotic Plaque Markers in Risk Prediction of Diabetic Nephropathy
}

\author{
V. $\operatorname{Khot}^{1}$, K.S. $\operatorname{Yadav}^{1}$, V.A. Haldankar ${ }^{1}$ and A.K. Bhutey ${ }^{2}$ \\ ${ }^{1}$ Department of Biochemistry, School of Medicine, D Y Patil University, \\ Navi Mumbai-400706, India \\ ${ }^{2}$ Dr.PDM Medical College, Amravati-444603, India \\ *Corresponding author
}

A B S T R A C T

Keywords

Diabetes mellitus, diabetic

nephropathy, microalbuminuria, gene expressions.

Article Info

Accepted:

12 December 2016

Available Online:

10 January 2017
About 10 to $40 \%$ Type 2 diabetes (T2DM) and $30 \%$ Type 1 diabetes (T1DM) suffer from kidney failure, increases huge financial burden for care. Patients with uncontrolled diabetes prone to ESRD, require kidney transplantation, haemodialysis or peritoneal dialysis which adds psychological distress. Present research work. It is prospective study includes 241 subjects conducted at the Department of Biochemistry, D Y Patil University, Navi Mumbai, India. Early detection of Kidney injury evaluated by IL-6, IL-10 CD36 and LDLr gene expressions in T2DM with microalbuminuria by rt-PCR and biochemical parameters by spectrophotometry methods. In study groups all renal parameters and lipids are within normal range except albumin/creatinine ratio $(p<.012)$, e-GFR $(p<.00)$ and cholesterol $(\mathrm{p}<.00)$. Descriptive and post hoc test analysis showed high significance (p<.00) for IL-6, IL-10, CD36 and LDLr. Screening biochemical renal parameters are not enough to prevent DN even in microalbuminuria. Early detection of gene expressions of IL-6, IL-10 and CD36, LDLr predict forthcoming risk of kidney injury. Early intervention may prevent morbidity of kidney in type II diabetes associated diabetic nephropathy.

\section{Introduction}

Diabetes has become a common global health problem that affects $>170$ million people worldwide. It is one of the leading causes of death and disability. World Health Organization estimated that by 2030 (Bethesda, 2007 and King et al., 1993), the number will rise to 366 million. DM is associated with long-term complications that affect almost every organ of the body, kidney, liver heart etc. T2DM is a complex polygenic disorder in which common genetic variants interact with environmental factors to unmask the disease.
Genetic factors are known to play an important role in the development of DN, atherosclerotic plaque etc (Eoin Brennan et al., 2013). Researchers found that plasma concentrations of inflammatory molecules including proinflammatory cytokines IL-6, IL-10 are elevated in diabetic patients (Pickup J. C., 1997). Recent studies have shown that concentrations of these substances increase with the progression of nephropathy (Bruno et al., 2003 and Krolewski et al., 2013). In this study the similar observations are observed. 
Shikano et al., (2000), studied usefulness of IL-6 and IL10 diabetic nephropathy showed that increased adipose tissue IL-6 mRNA may be the cause of insulin resistant humans and the elevated mRNA levels correlated with reduced rates of insulin stimulated glucose disposal (Bastard et al., 2002) which further might progress into insulin resistance diabetes nephropathy.

Study done by researchers suggested that an adverse lipid profile might cause nephropathy in both type 1 and type 2 diabetic patients (Bonnet et al., 2000 and Chaturvedi et al., 2001). Single-gene (Mendelian) disorders with large effects (Proctor et al., 2006) are the most dramatic examples of the genetic contributions to lipid deposition in arteries. Dysregulation of cholesterol metabolism has also been linked to lipotoxicity and lipid accumulation in diabetes. Cholesterol influx into cells is mediated by several independent receptors, including scavenger receptor class A (SR-A1), class B (CD36), lectin-like oxLDL receptor-1 (LOX-1 or OLR-1 (Urahama, 2008), and LDL receptor (Nosadini et al., 2011). CD36 is a transmembrane protein of the class B scavenger receptor family and is involved in multiple biological processes (Febbraio et al., 2001). Abnormal lipoprotein metabolism noted by Hirano which stated that increased CVD risk lead to cause dyslipidemia is multifactorial and complex (Hirano, 2014).

Previous studies documented that all multiple lipoprotein abnormalities described in diabetic patients with nephropathy become more accentuated with increasing urinary albumin excretion (Gross et al., 2005). Hyperglycaemia-induced synthesis of CD36 protein in macrophages has been associated with increased uptake of ox-LDL by macrophages and foam cell formation in atherosclerotic lesions in people with diabetes. While diabetic cardiovascular complications are closely linked epidemiologically with albuminuria and DN, a role for CD36 in $\mathrm{DN}$ and renal pathophysiology has not to our knowledge been described to date (Febbraio et al., 2001). High ambient glucose has been shown to induce CD36 protein synthesis in macrophages (Griffin et al., 2001). CD36 expression in proximal tubular epithelial cell (PTECs) is associated with the diabetic condition and appears to be independent of degree of proteinuria and renal failure. Indeed, Susztak, et al., (2005) emphasized that increased CD36 expression in PTECs in DN was due to hyperglycemias, and concluded that high blood glucose stimulates CD36 expression in vitro (Susztak et al., 2005).

Literature survey found that researchers identified risk genes and loci associated with DN. So far, only several genes and loci have been identified, none of them showed a strong association with DN. However, DN is not clinically detectable until significant kidney damage has developed, highlighting the need to identify early-stage biomarkers. Therefore, a better study design with a larger sample size to identify candidate gene/s by expressions in DN are still needed.

\section{Materials and Methods}

In this study includes 241 subjects (118 male, 123 women, and age ranges 30-70 years) were included after screening for T2DM by measurement of blood glucose in fasting, post-prandial, glycosylated haemoglobin and microalbumin in urine. Subjects distributed after written consent and enrolled as per inclusion/exclusion criteria. All measurements before distribution were documented in data sheet. Categorization of subjects in three study groups were done on the basis of T2DM duration 3-5 years, Glycosylated 
haemoglobin level $(\mathrm{HbA} 1 \mathrm{c}) \geq 7.0 \%$ with fasting blood glucose $\geq 126 \mathrm{mg} / \mathrm{dl}$ ) and microalbuminuria $(30-300 \mathrm{mg} / \mathrm{dl})$ in study group. Equal numbers of healthy volunteers enrolled in control group. Blood samples were processed for renal parameters \& RtPCR to check expressions of IL-6, IL-10, CD36 and LDLr.

\section{Results and Discussion}

Fasting blood glucose (FBS), Post- prandial blood glucose (PPBS), Glycosylated haemoglobin (A1C) and urinary microalbumin gives an idea about diabetes progression of individual. Since these are screening parameters for subject selection, there was a significant difference between control and study groups, p-value (<.00). In study group subjects no significant difference has been observed.

Diabetes and associated complications represent a significant health and economic burden, and given the emerging epidemics of obesity and diabetes in children and adolescents these increases in prevalence are expected to continue (Bethesda MD, 2007). Diagnosis of DN is typically made using clinical criteria (albuminuria, serum creatinine) rather than invasive renal biopsy.

Despite the large body of evidence for a heritable genetic component to nephropathy in type 1 and type 2 diabetes, the underlying genetic mechanisms remain poorly understood, with no robust $\mathrm{DN}$ candidate genes yet identified. Outcome of this study suggest that novel biomarker may play an important role in the progression and development of DN (Krolewski et al., 2013).

Study done by Nobuko Harita et al., (2009), showed that lower serum creatinine increased the risk of T2DM. Skeletal muscle is major target tissue of insulin and its resistance leads to the development of T2DM (Zierath et al., 2000). Creatinine is commonly used to determine GFR. In our study average serum creatinine reported within the normal range in control and study groups, similar findings were reported by Harita et al., (2009), urinary excretion of creatinine was almost two fold higher in both the study groups against the control group. Further post hoc analysis within study groups ( $<45$ years and $>45$ years) irrespective of gender showed significant, $\mathrm{p}$ value (<.00 and .00). In this study it was found no significant difference in urine creatinine was observed between control and study groups.

Micro-albuminuria is a gold standard parameter in diagnosis of renal diseases. Albumin/ creatinine ratio (ACR) is greater than or equal to 2.5 (men) or 3.5 (women), or albumin concentration greater than or equal to $20 \mathrm{mg} / \mathrm{L}$ is significant observation in diagnosis of renal diseases. Literature survey reveals that early stage of kidney disease demonstrates an abnormal ACR. This study reported marginally significant difference of ACR between control and study groups. Further post hoc analysis also showed similar observations between control, less than 45 years and above 45 years. These observations do not indicate any confirmatory outcome. So it was recommended to undertake study on a larger population to achieve final conclusion. After literature survey it was fond that ACR is an important marker in diagnosis of DN but values reported in this study does not support.

It was recommend by the American Diabetes Association and the National Institutes of Health that in all the people with diabetes for detection of kidney dysfunction, e-GFR must be calculated from serum Creatinine at least once a year. In this study e-GFR was calculated by MDRD (Modification of diet in renal disease) study group equation (Levey et 
al., 1999). There is significant difference between control and study groups $(\mathrm{p}<.00)$. Further analysis by post hoc test within the study groups ( $<45$ years and $>45$ years) and control showed significant difference, $\mathrm{p}$ value $(<.00)$. Therefore measurement of $\mathrm{e}$ GFR is useful indicator in monitoring diabetic nephropathy associated with T2DM. All above statements are tabulated in table no $1 \&$ 2.

IL-6 is one of the most extensively studied pro-inflammatory cytokines (Suzuki D, et al., 1995). Cortical mRNA expression of IL-6 is increased in diabetic kidney in comparison with normal rodents and is positively associated with elevated urinary concentrations of albumin (Navarro et al., 2006). Similarly, other researcher published work on interstitial expression of IL-6 mRNA in human renal tissue from individuals with diabetes, correlates with histological features of interstitial injury (Suzuki et al., 1995). IL10, an important Th2 cytokine, exerts predominantly anti-inflammatory and immunosuppressive effects (Zimmet, 1999). In present study Data analysed by SPSS showed positive expression of IL-6 and IL-10 in both the groups irrespective of gender. It indicates that there is inflammation and its degree of severity is correlated with renal injury in T2DM.

In this study descriptive statistics (table1) within groups showed significant difference only for HDL $(\mathrm{P}<.00)$ \& $\mathrm{LDL} / \mathrm{HDL}$ ratio $(\mathrm{P}<.00)$. All other lipid parameters $\mathrm{p}$-values are non-significant. High density lipoprotein cholesterol (HDL-C) is protective against the development of coronary artery disease (CAD) and microalbuminuria (Zierath et al., 2000). In this study it was found similar results in HDL \& HDL/LDL ratio. Cholesterol, triglyceride, LDL and VLDL levels disagreed with the outcomes of KMA Aziz et al., (2013) study on diabetic nephropathy. In this study high degree of significance, $\mathrm{p}$ value $(<.000-.005)$ was found in proinflammatory cytokines (IL6 \& IL10), scavenger receptor (CD36) protein and atherosclerotic (LDLr) in both study groups (Table1 and 2).

In 1995, Suzuki et al., (1995) reported that serum levels of IL-6 were significantly higher in patients with T2DN than the levels observed in diabetic patients without nephropathy, which suggests that IL-6 may have a role in the pathogenesis of DN. Later, Suzuki et al., (1995) performed situ hybridization of IL-6 in diabetic nephropathy, analyzed kidney biopsies in patients with DN by high-resolution in situ hybridization. Outcome of further experiment showed that cells infiltrating the mesangium, interstitium, and tubules were positive for mRNA encoding IL-6. Also they found a relationship between the severity of diabetic glomerulopathy (mesangial expansion) and expression of IL-6 mRNA in glomerular cells (mesangial cells and podocyte), which indicated that IL-6 may affect the dynamics of extracellular matrix surrounding those cells. Many in-vitro studies have confirmed that IL6 affects extracellular matrix dynamics at mesangial and podocyte levels, stimulates mesangial cell proliferation, increases fibronectin expression, and enhances endothelial permeability. This mechanism has been proved in the development of kidney injury in patients with T2DM. Moreover, high serum and urinary concentrations of IL-6 are associated with greater albuminuria in patients with DN; however, serum and urinary levels do not correlate with each other (Shikano et al., 2000, and Navarro et al., 2006).

IL-10 plays an essential role in the pathogenesis of DN. Mesangial expansion has also been found to be attributable to hyperglycaemia related inflammation 
(Myśliwska et al., 2005 and Proctor et al., 2006). Mesangial cells are the major local source of IL-10 in the normal adult kidney. Several studies have demonstrated the association between up regulation of IL-10 and the pathophysiology of various kidney diseases such as mesangio-proliferative glomerulonephritis (Yano et al., 1997; Niemir et al., 1998; Sinuai et al., 2006). Increased serum levels of circulating IL-10 have been found and correlate with albuminuria and diabetic nephropathy IL-10 plays an essential role in the pathogenesis of DN. These factors may slow down the course of diabetic nephropathy through a reduction of the inflammatory processes. The study done by Inna Sinuai et al., (2006) suggested that IL-10 gene expression and IL-10 induced signalling pathways has important role in the regulation and maintenance of normal renal function. In this study IL6 \& IL10 expressions are observed which is relates to the conclusion of several research papers referred in literature. In this study it was found significant P-values of IL-6 \& IL-10 ( $\mathrm{p}<.000$-.005) in all study groups. Dyslipidimia is a risk factor for development and progression of microalbuminuria. In this study estimated lipids showed values within reference interval but LDLr \& CD36 expressions were observed at an early stage of DN. High degree of significance was found in both LDLr and CD36 ( $p<.000)$ also, which was shown in table 3 .

CD 36 is a trans-membrane protein of the class $b$ scavenger receptor family $\&$ is involved in multiple biological processes (Febbraio et al., 2001). High ambient glucose has been shown to induce CD36 protein synthesis in macrophages, because CD36 protein was markedly increased in proximal tubules in human diabetic nephropathy (Susztak et al., 2005). In our study similar findings has been noted with significant level of expressions in the study group compared to control, which indicate proximal tubular injury in subjects. Glycosylated hemoglobin and albuminuria compared with CD36 showed significant results which indicate that hyperglycemia in the blood circulation lead to progression of renal injury. CD36 is intimately involved in lipid metabolism and has been strongly implicated in pathological conditions associated with metabolic disregulation, including obesity, insulin resistance, diabetes, diabetic nephropathy and atherosclerosis (Febbraio et al., 2001 and, Griffin et al., 2001). The expressions of LDLr molecules involved in low-density lipoprotein receptor (LDLr) pathway and podocyte injury. The mean of LDL receptors observed expressed in this study, similar results were published by Laurence Duvillard et al., (2003).

CD36 is intimately involved in lipid metabolism and homoeostasis and has been strongly implicated in pathological conditions associated with metabolic dysregulation, including obesity, insulin resistance, diabetes, diabetic nephropathy and atherosclerosis (Suzuki et al., 1995 and, Yano et al., 1997). Circulating form of CD36 was identified in human plasma as a novel biomarker for T2DM (Handberg et al., 2006). Hyperglycaemia-induced synthesis of CD36 protein has been associated with increased uptake of LDL lead in atherosclerotic lesions in people with diabetes (Febbraio et al., 2001 and, Griffin et al., 2001). Researcher Susztak $\mathrm{K}$, et al., (2005) reported a new functional role for CD36 scavenger receptor in tubular epithelial apoptosis associated with tubular degeneration and progression of DN. Thus CD36 could have a central role in triggering diabetic nephropathy which is one of the observations of this study. Despite immediate clinical implications for the treatment of people with kidney problems, this research may help in understanding how hyperglycaemia damages the kidney. In 
particular, it highlights how important it is to keep blood glucose levels within reference range. A detailed review was published on role of novel gene biomarkers in early diagnosis of DN (Nahar et al., 2014).

Table.1 Descriptive statistical analysis of renal parameters, and lipid parameters by R software within groups

\begin{tabular}{|l|c|c|c|c|c|c|}
\hline \multirow{3}{*}{ Study parameters } & \multicolumn{9}{|l|}{ Study groups } & \multicolumn{2}{c|}{$\begin{array}{c}\text { More than } 45 \\
\text { years }\end{array}$} \\
\cline { 2 - 8 } & \multicolumn{2}{|c|}{ Control } & 45 years and less & \multicolumn{2}{c|}{ yean } \\
\cline { 2 - 8 } & Mean & SE & Mean & SE & Mean & SE \\
\hline Urine Creatinine & 60.99 & 4.335 & 121.06 & 9.231 & $134 . .65$ & 13.960 \\
\hline Albumin/ creatinine ratio & 0.44 & 2.113 & 3.35 & 3.556 & 3.35 & 2.623 \\
\hline Blood urea nitrogen & 10 & 0.284 & 10 & 0.237 & 11 & 0.335 \\
\hline Uric Acid & 4.8 & 0.112 & 5.0 & 0.203 & 5.3 & 0.139 \\
\hline Serum Creatinine & 0.79 & 0.02 & 0.716 & 0.019 & 0.854 & 0.023 \\
\hline e-GFR & 100 & 2.46 & 94 & 114 & 90 & 2.077 \\
\hline Total Cholesterol & 117 & 2.73 & 178 & 5.9 & 190 & 4.68 \\
\hline Triglyceride & 137 & 3.7 & 139 & 7.9 & 160 & 10.8 \\
\hline HDL Cholesterol & 44.66 & 0.70 & 38.80 & 0.711 & 41.42 & 1.0 \\
\hline Low density Lipoprotein & 101.22 & 1.061 & 113.21 & 4.41 & 130.5 & 3.69 \\
\hline Cho/HDL ratio & 5.04 & 0.121 & 4.64 & 0.135 & 4.79 & 0.14 \\
\hline LDL/HDL ratio & 3.60 & 0.103 & 2.956 & 0.106 & 3.306 & 0.120 \\
\hline VLDL & 27.59 & 0.704 & 27.828 & 1.59 & 32.1 & 2.17 \\
\hline
\end{tabular}

Table.2 P Value of Post Hoc Tests of renal parameters and lipid parameters within groups and between the groups (Tukey HSD).

\begin{tabular}{|l|c|c|c|c|c|c|}
\hline \multirow{2}{*}{$\begin{array}{l}\text { Dependent } \\
\text { Variable }\end{array}$} & \multicolumn{2}{|l|}{ Control group } & \multicolumn{2}{l|}{$<45$ years group } & \multicolumn{2}{l|}{$>45$ years group } \\
\cline { 2 - 7 } & $<45 \mathrm{yrs}$ & $\begin{array}{c}>45 \\
\text { yrs }\end{array}$ & Control & $\begin{array}{c}>45 \\
\text { yrs }\end{array}$ & Control & $<45$ yrs \\
\hline Serum Creatinine & .034 & .074 & .034 & .00 & .074 & .00 \\
\hline ACR & .008 & .420 & .008 & .186 & .420 & .186 \\
\hline e-GFR & .00 & .012 & .00 & .00 & .012 & .00 \\
\hline BUN & .751 & .040 & .751 & .197 & .040 & .197 \\
\hline HDL Cholesterol & .000 & .000 & .000 & .071 & .000 & .071 \\
\hline Triglyceride & .080 & .086 & .080 & .089 & .086 & .089 \\
\hline LDL/HDL ratio & .000 & .138 & .000 & .064 & .138 & .064 \\
\hline
\end{tabular}

Abbreviations: SD: standard deviation, SE: standard error, PV: P value (Post hoc test). Data are mean + SD with range in parenthesis or absolute number of patients. 
Table.3 Post hoc test between study groups and inflammatory markers (Tukey HSD)

\begin{tabular}{|l|c|c|c|c|c|c|}
\hline \multirow{2}{*}{$\begin{array}{l}\text { Dependent } \\
\text { Variable }\end{array}$} & \multicolumn{2}{|l|}{ Control group } & \multicolumn{2}{l|}{$<45$ years group } & \multicolumn{2}{l|}{$>45$ years group } \\
\cline { 2 - 7 } & $<45$ yrs & $\begin{array}{c}>45 \\
\text { yrs }\end{array}$ & Control & $\begin{array}{c}>45 \\
\text { yrs }\end{array}$ & Control & $<45$ yrs \\
\hline CT of IL-6 & .00 & .00 & .00 & .00 & .00 & .00 \\
\hline CT of IL-10 & .00 & .00 & .00 & .005 & .00 & .005 \\
\hline CT of CD36 & .00 & .00 & .00 & .00 & .00 & .00 \\
\hline CT of LDLr & .00 & .00 & .00 & .00 & .00 & .00 \\
\hline
\end{tabular}

CT: threshold cycle quantification by rt-PCR.

It was concluded that early detection of renal injury in T2DM patients with routine biochemical parameters create dilemma. But when these results evaluated with gene expressions (IL-6, IL-10, CD36 and LDLr) and output of this exercise may help in confirmation of diagnosis. This observation strongly support risk prediction of DN. Early measurement of IL-6, IL-10, CD36 and LDLr may prevent morbidity \& mortality. The present study was carried out in limited number of T2DM subjects. Further extensive research on large number of subjects with population diversity has been recommended.

\section{Acknowledgement}

We would like to express our sincere thanks to medical administrators, faculties and paramedical staff of D.Y. Patil Medical College, Navi Mumbai. We wish thanks to Dr Sakharam Muley for statistical analysis. Special thanks to the subjects who have participated in this research work, without their participation, this project would not have been possible.

\section{References}

Aziz, K.M.A., and M.A.A. Al-Qahtani. 2013. Association between Non-HDL and HDL Cholesterol with microalbuminuria in patients with Diabetes. J. Dialectol., 1-4.

Bastard, J.P., Maachi, M., Van, N., Hieu, J.T., Jardel, C., Bruckert, E., et al. 2002. Adipose tissue IL-6 content correlates with resistance to insulin activation of glucose uptake both in vivo and in vitro. J. Clin. Endocrinol. Metab., 87: 20842089.

Bethesda, M.D. 2007. United States Renal Data System. USRDS 2007 Annual Data Report.

Bonnet, F. and Cooper, M.E. 2000. Potential influence of lipids in diabetic nephropathy: Insights from experimental data and clinical studies. Diabetes Metab., 26: 254-64.

Bruno, G., Merletti, F., Biggeri, A. 2003. Progression to overt nephropathy in type 2 diabetes: the Casale Monferrato study. Diabetes Care, 26(7): 21502155.

Chaturvedi, N., Fuller, J.H., Taskinen, M.R. 2001. Differing associations of lipid and lipoprotein disturbances with the macrovascular and microvascular complications of type 1 diabetes. Diabetes Care, 24: 2071-7.

Eoin Brennan, Caitríona Mc Evoy, Denise Sadlier, Catherine Godson and Finian Martin. 2013. The Genetics of Diabetic Nephropathy. Genes (Basel), 4(4): 596619. 
Fadden, K., Rifai, A. 1997. Phenotypic characterization of cytokine expression in patients with $\operatorname{IgA}$ nephropathy. J. Clin. Immunol., 17: 396-403.

Febbraio, M., Hajjar, D.P., Silverstein, R.L. Febbraio, M., Hajjar, D.P., Silverstein, R.L. 2001. CD36: A class B scavenger receptor involved in angiogenesis, atherosclerosis, inflammation, and lipid metabolism. J. Clin. Invest., 108: 785791.

Griffin, E., Re, A., Hamel, N., Fu, C., Bush, H., Griffin, E., et al. 2001. A link between diabetes and atherosclerosis: Glucose regulates expression of CD36 at the level of translation 7(7): 840-6.

Gross, J.L., de Azevedo, M.J., Silveiro, S.P., Canani, L.H., Caramori, M.L., Zelmanovitz, T. 2005. Diabetic nephropathy: Diagnosis, prevention, and treatment. Diabetes Care, 28: 164 525.

Handberg, A., Levin, K., Hojlund, K., BeckNielsen, H. 2006. Identification of the oxidized low-density lipoprotein scavenger receptor CD36 in plasma: a novel marker of insulin resistance. Circulation, 114(11):1169-76

Harita, N., Hayashi, T., Sato, K.K., Yoneda, T., Endo, G., Kambe, H. 2009. Lower serum creatinine is a new risk factor of type 2 diabetes: the Kansai healthcare study. Diabetes care, 32: 424-426

Hirano. 2014. Abnormal lipoprotein metabolism in diabetic nephropathy. Clin. Exp. Nephrol., 18(2):206-9

King, H., Rewers, M. 1993. Global estimates for prevalence of diabetes mellitus and impaired glucose tolerance in adults: WHO Ad Hoc Diabetes Reporting Group. Diabetes Care, 16: 157-177.

Krolewski, A.S., Niewczas, M.A., Skupien, J., Gohda, T., Smiles, A., Eckfeldt, J.H., Doria, A., Warram, J.H. 2014. Early progressive renal decline precedes the onset of microalbuminuria and its progression to macro albuminuria. Diabetes Care, 37(1): 226-34

Laurence Duvillard, Emmanuel Florentin, Gérard Lizard, Jean-Michel Petit, Françoise Galland, Serge Monier, et al. 2003. Cell Surface Expression of LDL Receptor Is Decreased in Type 2 Diabetic Patients and Is Normalized by Insulin Therapy. Diabetes Care, 6(5): 1540-1544.

Levey, A.S., Bosch, J.P., Lewis, J.B., Greene, T., Rogers, N., Roth, D. 1999. A more accurate method to estimate glomerular filtration rate from serum creatinine: a new prediction equation. Modification of Diet in Renal Disease Study Group. Ann. Intern. Med., 130(6):461-70.

Myśliwska, J., Zorena, K., SemetkowskaJurkiewicz, E., Rachoń, D., Suchanek, H. 2005. High levels of circulating interleukin-10 in diabetic nephropathy patients. Eur Cytokine Netw, 16: 117122.

Nahar, A., Yadav, K.S., Suresh Kumar, P. 2014. Novel biomarkers of early renal injury in diabetes. D Y Patil J. Health Sci., 2(3), 35-39.

Navarro, J.F., Milena, F.J., Mora, C., Leon, C., Garcia, J. 2006. Renal proinflammatory cytokine gene expression in diabetic nephropathy: Effect of angiotensin-converting enzyme inhibition and pentoxifylline administration. Am. J. Nephrol., 26: 562-570.

Niemir, Z.I., Ondracek, M., Dworacki, G., Stein, H., Waldherr, R., Ritz, E., et al. 1998. In situ upregulation of IL-10 reflects the activity of human glomerulonephritides. Am. J. Kidney Dis., 2: 80-92.

Nosadini, R. and Tonolo, G. 2011. Role of oxidized low density lipoproteins and 
free fatty acids in the pathogenesis of glomerulopathy and tubulointerstitial lesions in type 2 diabetes. Nutr. Metab. Cardiovasc. Dis., 21: 79-85.

Pickup, J.C., Mattock, M.B., Chusney, G.D., Burt, D. 1997. NIDDM as a disease of the innate immune system: association of acute-phase reactants and interleukin6 with metabolic syndrome $\mathrm{X}$. Diabetologia, 40(11):1286-1292.

Proctor, G., Jiang, T., Iwahashi, M., Wang, Z., Li, J., Levi, M. 2006. Regulation of renal fatty acid and cholesterol metabolism, inflammation, and fibrosis in Akita and OVE26 mice with type 1 diabetes. Diabetes, 55: 2502-2509.

Shikano, M., Sobajima, H., Yoshikawa, H., Toba, T., Kushimoto, H., Katsumata, H., et al. 2000. Usefulness of a highly sensitive urinary and serum IL-6 assay in patients with diabetic nephropathy. Nephron., 85: 81-85.

Sinuai, I., Averbukh, Z., Gitelman, I., Rapoport, M.J., Sandbank, J., Albeck, M., et al. 2006. Mesangial cells initiate compensatory renal tubular hypertrophy via IL-10-induced TGFbeta secretion: effect of the immunomodulator AS101 on this process, Am. J. Physiol. Renal Physiol., 291: 384-39.

Susztak, K., Ciccone, E., McCue, P., Sharma, K., Bottinger, E.P. 2005. Multiple Metabolic Hits Converge on CD36 as Novel Mediator of Tubular Epithelial Apoptosis in Diabetic Nephropaty PLoS Med., 2: e45.

Suzuki, D., Miyazaki, M., Naka, R., Koji, T., Yagame, M., Jinde, K., et al. 1995. In situ hybridization of interleukin 6 in diabetic nephropathy. Diabetes, 44 : 1233-1238.

Urahama, Y., Ohsaki, Y., Fujita, Y., Maruyama, S., Yuzawa, Y., Matsuo, S., et al. 2008. Lipid droplet-associated proteins protect renal tubular cells from fatty acid-induced apoptosis. Am. J. Pathol., 173: 1286-1294.

Zierath, J.R., Krook, A., WallbergHenriksson, H. 2000. Insulin action and insulin resistance in human skeletal muscle. Diabetologica, 43; 821-835.

Zimmet, P.Z. 1999. Diabetes epidemiology as a tool to trigger diabetes research and care. Diabetologia, 42(5): 499518.

\section{How to cite this article:}

Khot, V., K.S. Yadav, V.A. Haldankar and Bhutey, A.K. 2017. Vitality of Pro-Inflammatory Cytokine, Scavenger Receptor Proteins and Atherosclerotic Plaque Markers in Risk Prediction of Diabetic Nephropathy. Int.J.Curr.Microbiol.App.Sci. 6(1): 116-124. doi: http://dx.doi.org/10.20546/ijcmas.2017.601.015 